\title{
Colchicine as a Potential Therapeutic Agent Against Cardiovascular Complications of COVID-19: an Exploratory Review
}

\author{
Christodoulos Papadopoulos ${ }^{1}$ (D) - Dimitrios Patoulias ${ }^{2}$ - Eleftherios Teperikidis ${ }^{1}$ - Dimitrios Mouselimis ${ }^{1}$. \\ Anastasios Tsarouchas ${ }^{1}$ - Maria Toumpourleka ${ }^{1} \cdot$ Aristi Boulmpou $^{1} \cdot$ Constantinos Bakogiannis $^{1} \cdot$ Michael Doumas $^{2,3}$. \\ Vassilios P. Vassilikos ${ }^{1}$
}

Accepted: 17 July 2020 / Published online: 4 August 2020

(C) Springer Nature Switzerland AG 2020

\begin{abstract}
Coronavirus disease-19 (COVID-19) may result in serious complications involving several organ systems, including myocardial tissue. An exaggerated host inflammatory response, described as a cytokine storm, has been linked to play a major role in these complications. Colchicine and other pharmaceutical agents have been proposed to counter the cytokine storm and improve outcomes. In this exploratory review, we utilized a PubMed and Cochrane Database search aiming to identify the biochemical characteristics of the cytokine storm as well as to identify the potential effect of colchicine on these inflammatory biomarkers. The research yielded 30 reports describing the characteristics of the cytokine storm and 44 reports describing the effect of colchicine on various inflammatory biomarkers. According to our research, colchicine may be an agent of interest in the treatment of COVID-19 via its anti-inflammatory properties. However, there are potential drug interactions with cytochrome P450 3A4 inhibitors resulting in acute colchicine toxicities. Additionally, there is scarce evidence regarding the efficacy of colchicine in the acute phase of disease, since most trials evaluated its effect in chronic conditions. In this direction, our team proposes three different hypotheses for evaluating the place of colchicine in the treatment of COVID- 19.
\end{abstract}

Keywords COVID-19 $\cdot$ Coronavirus $\cdot$ Virus $\cdot$ Colchicine $\cdot$ Cardiovascular disease $\cdot$ CVD

\section{Introduction}

As of December 2019, a novel coronavirus named severe acute respiratory syndrome (SARS) coronavirus (CoV)-2 has emerged in Wuhan Province in China [1]. Since then, SARS CoV-2 has demonstrated high human to human transmission rates and has developed into a worldwide pandemic

This article is part of the Topical Collection on Covid-19

Christodoulos Papadopoulos

chpapado@auth.gr; chrpapado@gmail.com

1 Third Department of Cardiology, Hippokration University Hospital, Aristotle University of Thessaloniki, Konstantinoupoleos 49 Str., 54643 Thessaloniki, Greece

2 Second Propedeutic Department of Internal Medicine, General Hospital "Hippokration", Aristotle University of Thessaloniki, Thessaloniki, Greece

3 VA Medical Center and Georgetown University, Washington, DC, USA
[2]. To date (April 26, 2020), there have been almost 2.8 million confirmed cases as well as over 193,722 deaths attributed to coronavirus disease-19 (COVID-19) according to WHO [3]. Since the original outbreak, a large number of reports have emerged describing all relevant aspects of COVID19 [4].

The focus of this report is on the exaggerated host inflammatory response, most often described as a cytokine storm that is reported in critically ill patients [5]. This seems to play a major detrimental role in the development of complications and ultimately death associated with COVID-19 [5, 6]. Recent focus has therefore been placed on identifying antiinflammatory pharmaceutical agents that could be repurposed in an attempt to reduce complications and improve the survival rates of the infection. One such molecule is colchicine, an agent that has been used for several years in the treatment of auto-immune diseases, most relevantly that of post-viral pericarditis [7].

Colchicine is a phytochemical compound that was originally derived from autumn crocus. The use of this plant in the treatment of inflammatory conditions may date back to 1500 


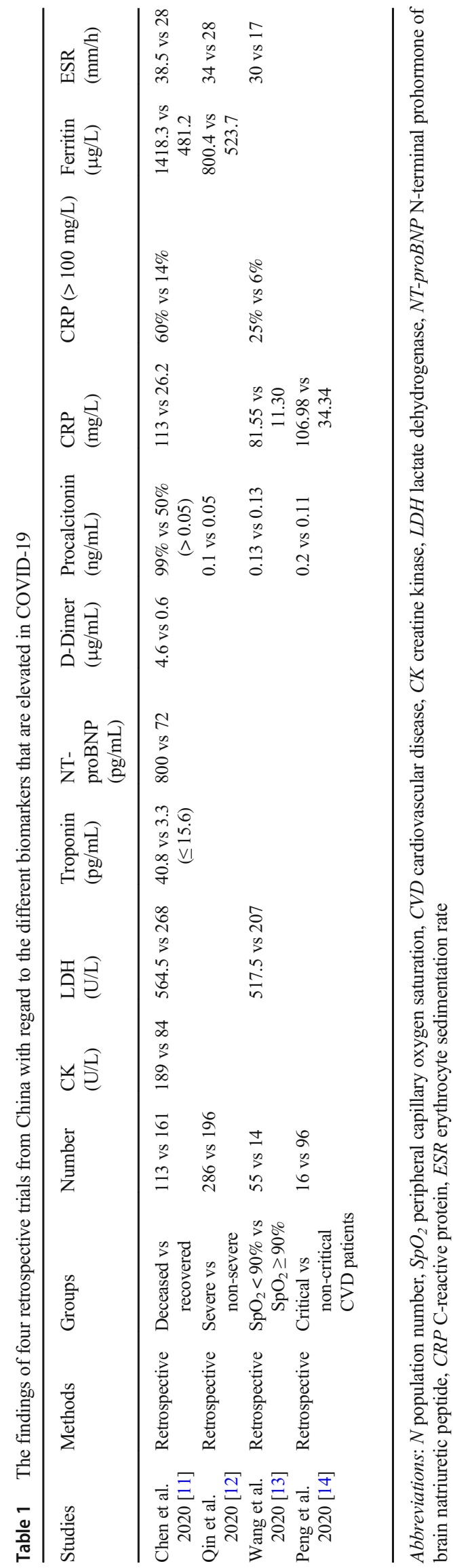

$\mathrm{BC}$ [7]. In modern medicine, it has been used for several decades in the treatment of gout, Behcet's disease, Mediterranean fever, and pericarditis [7]. Colchicine inhibits microtubule polymerization, thereby affecting a variety of cellular processes, such as the maintenance of shape, signaling, division, migration, and cellular transport [8]. Colchicine has been described to modulate several pro- and antiinflammatory pathways [9], such as the inhibition of activation and migration of neutrophils as well as interference with the neutrophil inflammasome complex, resulting in inhibition of interleukin-1b (IL-1b) [10].

\section{Methods}

A dual search of PubMed and the Cochrane Database was performed on April 2, 2020. The initial search was aimed at identifying reports describing the cytokine storm induced by COVID-19 and included the terms: "COVID-19," "Coronavirus," "SARS CoV-2," "Inflammation," "Inflammatory response," and "Cytokine storm." The terms were paired in every possible combination using the Boolean operator "AND." The second search was aimed at identifying reports describing the efficacy of colchicine in the treatment of post-viral pericarditis as well as other myocardial conditions related to inflammation. In this search, the search term "Colchicine" was combined using again the Boolean operator "AND" with each one of the terms "Pericarditis," "Myocarditis," and "Viral." The search was limited to the inclusion of keywords within the title and abstract of each report.

\section{Results}

A total of 46 reports were identified in our primary search. After title and abstract review, 16 reports were excluded as irrelevant to the topic, leaving 30 reports for full-text review. A total of 75 reports were identified in our secondary search. After title and abstract review, 31 reports were excluded as irrelevant to the topic, leaving 44 reports for full-text review.

\section{COVID-19 Cytokine Storm}

In severe cases of COVID-19, several laboratory values are elevated indicating an augmented inflammatory response. Table 1 presents the findings of four retrospective trials from China with regard to the different biomarkers that are elevated in COVID-19. Furthermore, these trials reported on the elevations of various inflammatory mediators, which are reported in Table 2. In severe cases, the cytokine storm seems to affect other organs as well. Liver injury was common in 79 non-ICU hospitalized COVID-19 patients [15], but that did not seem to 
be a prominent feature of COVID-19 [16]. Similarly, renal injury was not demonstrated in 116 patients [17]. There are however other reports of patients with COVID-19 with associated renal injury [18]. Acute cardiac injury associated with cardiac dysfunction and arrhythmias however seems to play a detrimental role in mortality [19]. As such, patients with prior cardiovascular disease (CVD) are considered to be at high risk of developing morbid complications [20]. Of particular interest was a case report of an otherwise healthy 53-year-old woman who developed cardiac complications related to COVID-19 without signs and symptoms of interstitial pneumonia [21]. Finally, patients with diabetes have been demonstrated to be at a higher risk of COVID-19 complications [22], which could be at least in part attributed to IL-6, which is already increased in conditions of chronic inflammation [23].

In conclusion, COVID-19 is a disease that seems to target the lungs and the cardiovascular and immune systems [24]. It is worth mentioning that in a report of three post-mortem biopsies, the lungs manifested significant pathological lesions while damages of the heart, vessels, liver, kidney, and other organs were also observed [25]. Interestingly, no evidence of SARS CoV-2 infection was observed in these organs.

The biochemical overview of the cytokine storm in critically ill COVID-19 patients has assisted in the identification of potential targets for anti-inflammatory treatment such as IL2 receptor, IL-6, IL-8, IL-10, and tumor necrosis factor (TNF). As such, inhibition of these targets along with a large number of different pharmaceutical agents has been hypothesized to be of potential benefit in weathering this cytokine storm. Table 3 lists some of these molecules.

It should be noted that the use of non-steroidal anti-inflammatory drugs (NSAIDs), ibuprofen in particular, has been cautioned due to the potential interaction with the angiotensin converting enzyme 2 (ACE 2) receptor [35]. ACE 2 has been previously described as the cellular binding site of the spiked proteins on the SARS CoV-2 surface [36]. However, this theory was highly scrutinized [37], while most authorities have issued statements declaring that there is insufficient evidence to make a recommendation against the use of NSAIDs. Overall, treatment with glucocorticoids, IL-6 antagonists, Janus kinase (JAK) inhibitors, and chloroquine/ hydroxychloroquine seems to be the mainstay of treatment, while a vast array of agents are currently being tested in clinical trials across the globe. Colchicine has recently received attention due to its anti-inflammatory mechanism of action that has been successfully utilized in the past in the treatment of pericarditis.

\section{Colchicine and Biomarkers of Inflammation}

We were able to locate 7 trials assessing the anti-inflammatory effect of colchicine in various cardiovascular conditions which are presented in Table 4. Biomarkers of inflammation 
Table 3 Molecules of potential benefit in weathering this cytokine storm

\begin{tabular}{ll}
\hline Studies & Investigated molecule \\
\hline Conti et al. 2020 [26] & IL-2 and IL-2R inhibitors \\
Conti et al. 2020 [27] B & IL-38 \\
Das et al. 2020 [28] & Arachidonic acid \\
Li et al. 2020 [29] & Lianhuaqingwen \\
Phadke et al. 2020 [30] & Angiotensin II receptor blockers and statins \\
Solaimanzadeh et al. 2020 [31] & Acetazolamide, nifedipine, and phosphodiesterase inhibitors \\
Stebbing et al. 2020 [32] & Baricitinib, ruxolitinib, and fedratinib \\
Sun et al. 2020 [33] & ACE and AT1R inhibitors \\
Zhang et al. 2020 [34] & Melatonin \\
\hline
\end{tabular}

Abbreviations: IL interleukin, ACE angiotensin converting enzyme, ATIR angiotensin type 1 receptor such as C-reactive protein (CRP), IL-1b, and IL-6 seem to be reduced by colchicine in chronic auto-immune conditions, while the evidence is somewhat conflicting in the acute phase of inflammatory cardiac disease. In the context of COVID-19, this could indicate a potential role of colchicine in the prevention of myocardial injury related complications. While the reports are inconsistent regarding the acute phase, these trials are always confounded by several factors regarding the nature of medical response, including the necessity for multi-drug treatments and invasive procedures, while placebo control groups are obviously out of the question. It is worth mentioning however that the effect on inflammatory biomarkers can be observed within hours of administration of colchicine. Finally, these results are consistent with data from trials assessing colchicine in non-cardiac auto-immune inflammatory conditions, such as Behcet's disease, where similar reductions have been observed. [45]

\section{Colchicine and Pericarditis}

Ten clinical trials assessing the efficacy of colchicine in the treatment of pericarditis were located and presented in Table 5. It should be noted that only two trials reported on the specific etiology underlying the development of pericarditis $[46,47]$, while the remaining eight relied on diagnostic criteria for pericarditis regardless of the pathological condition leading to it.

\section{Colchicine in the Prevention of Post-operative Complications Related to Inflammation}

We located fifteen clinical trials assessing the efficacy of colchicine after several different types of surgery. The primary outcome of these trials was a reduction of post-operative complications related to inflammation. Table 6 presents these trials.

\section{Systematic Reviews}

In a Cochrane Database Systematic Review, the use of colchicine in the treatment of pericarditis was examined [70]. Four clinical trials were included with a total of 564 patients. Colchicine treatment was associated with a lower recurrence of pericarditis while a higher percentage of patients experienced symptom relief.

In a systematic review including 15 trials with 3431 patients and assessing the anti-inflammatory properties of colchicine in various cardiovascular conditions, the authors concluded that colchicine may reduce adverse cardiovascular outcomes in a range of patients with CVD. Furthermore,

Table 4 Trials assessing the anti-inflammatory effect of colchicine in various cardiovascular conditions

\begin{tabular}{llrlll}
\hline Studies & Disease state & Number & Methods & Follow-up & Outcomes \\
\hline Akodad et al. 2017 [38] & STEMI & 44 & Colchicine vs no colchicine & 1 month & CRP was not significantly reduced \\
Deftereos et al. 2014 [39] & HF & 267 & Colchicine vs placebo & 6 months & CRP and IL-6 significantly reduced \\
Kajikawa et al. 2019 [40] & CAD & 28 & Colchicine vs placebo (cross-over) & 7 days & CRP significantly reduced \\
Martinez et al. 2015 [41] & ACS & 40 & Colchicine vs no colchicine & 2 doses prior to cardiac & IL-1b, IL-6, and IL-18 \\
& & & & catheterization & significantly reduced \\
Nidorf et al. 2007 [42] & CAD & 64 & Colchicine vs no colchicine & 4 weeks & CRP significantly reduced \\
Raju et al. 2011 [43] & ACS or stroke & 80 & Colchicine vs placebo & 1 month & CRP was not significantly reduced \\
Robertson et al. 2016 [44] & ACS & 30 & Colchicine vs no colchicine & 2 days & IL-1b significantly reduced
\end{tabular}

Abbreviations: $N$ population number, STEMI ST-elevation myocardial infarction, $H F$ heart failure, $C A D$ coronary artery disease, $A C S$ acute coronary syndrome, $C R P$ C-reactive protein, $I L$ interleukin 
colchicine reduced the rates of recurrent pericarditis, postpericardiotomy syndrome, and periprocedural atrial fibrillation following cardiac surgery [71].

A third systematic review of the same topic, which included five clinical trials and 795 patients, reached similar conclusions [72]. A fourth systematic review of seven clinical trials and 451 patients reached similar conclusions [73]. In this report, high-dose corticosteroids were associated with a detrimental effect. Finally, a fifth systematic review including seven clinical trials with 1275 patients also demonstrated the efficacy of colchicine in the prevention of both primary and recurrent pericarditis [74].

\section{Case Reports}

In a noteworthy case report, the authors presented a 37-yearold male patient with an acute exacerbation of Crohn's disease [75]. Following 2 weeks of multiple bowel movements associated with abdominal pain, which was not controlled by an increase in mesalamine and corticosteroid dose, the patient presented to the emergency department with a chief complaint of pleuritic chest pain. ST elevations were observed on electrocardiogram (EKG), while troponin I, erythrocyte sedimentation rate (ESR), and CRP were elevated. Cardiac magnetic resonance imaging (CMR) revealed early gadolinium enhancement consistent with myocarditis. The corticosteroid dose was further increased, and colchicine was started, with clinical improvement. The time between initiation of colchicine treatment and clinical improvement was not stated.

A second case report presented a patient with rheumatoid arthritis who developed rheumatoid pericarditis complicated with tamponade [76]. The patient demonstrated resistance to corticosteroid treatment and pericardiocentesis was performed twice. At that point, colchicine was initiated with subsequent clinical improvement, while corticosteroids were tapered down without recurrence of disease exacerbation.

\section{In vitro Data}

It is worth mentioning that in an in vitro experiment assessing colchicine in the treatment in coxsackievirus B3-induced myocarditis, colchicine had a detrimental effect causing complete destruction of the exocrine pancreas and enhancement viral load in both the heart and the pancreas [77]. However, the dose of colchicine used in this experiment was $2 \mathrm{mg} / \mathrm{kg}$, a rather high dose that could be responsible for signs and symptoms of acute toxicity. This was stated by formal correspondence to the authors [78]. It should be noted that the lethal dose (LD) 50 in mice is $>25 \mathrm{mg} / \mathrm{kg}$ [79], while lethal doses in humans have been reported with a little as $7 \mathrm{mg}$ [80]. Another trial reported a dose of $0.4 \mathrm{mg} / \mathrm{kg}$ on Chagas disease (CD)induced multifocal myocarditis and extensive fibrosis [81]. The authors reported that colchicine demonstrated a 


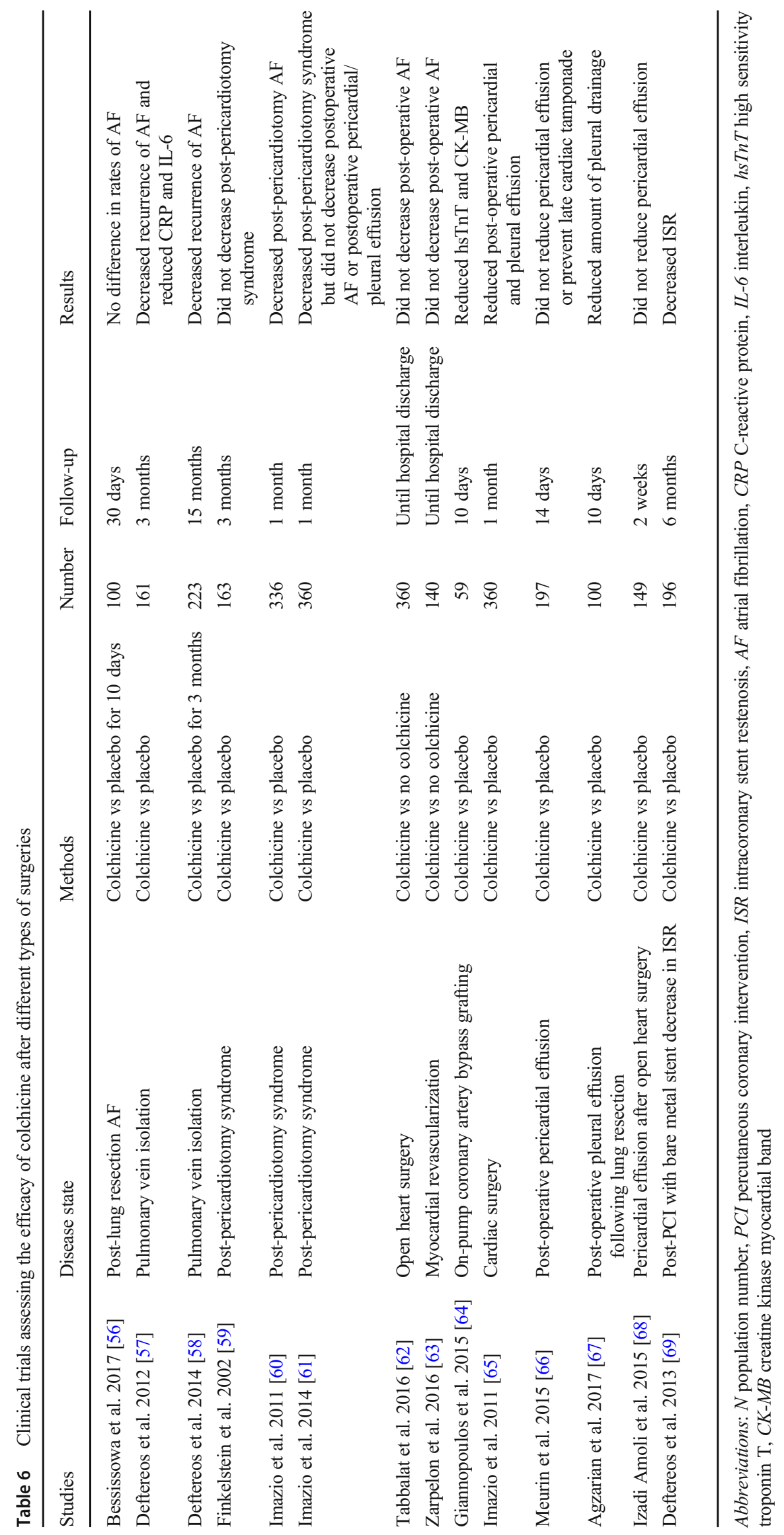


cardioprotective effect, as indicated by decreased interstitial myocardial fibrosis, increased intensity of MMP-2, and attenuated myocardial inflammation.

\section{Discussion}

Our results indicate that colchicine could play a role on the prevention as well as the management of the cytokine storm related complications associated with COVID-19. Caution however should be advised in terms of both the safety and efficacy of the medication. For example, 4745 patients were randomized to receive colchicine or placebo within 30 days after a myocardial infarction [82]. The authors reported that colchicine significantly lowered the risk of ischemic cardiovascular events. It should be noted however that pneumonia was reported as a serious adverse event in $0.9 \%$ vs $0.4 \%$ of treatment vs placebo patients $(P=0.03)$.

Furthermore, the pharmacokinetic profile of colchicine has to be taken into consideration. Colchicine is metabolized in the liver via the cytochrome P450 (CYP) 3A4 isoenzyme and $\mathrm{P}$-glycoprotein (P-gp). While the extent of hepatic metabolism does not seem to exceed 5\%, it is listed as a substrate, inhibitor, and inducer of several CYP450 isoforms [83], including $3 \mathrm{~A} 4$ [84], which could potentially lead to interactions with several medications. Renal and hepatic excretion of colchicine takes place through P-gp-mediated efflux [85]. The two postulated major routes of elimination of colchicine are enterohepatic recirculation and biliary excretion [86].

One trial reported that colchicine exposure was increased after a single dose of colchicine was administered with steadystate atorvastatin [87]. Furthermore, a trial that assessed the co-administration of colchicine with known inhibitors of CYP450 3A4 and P-gp (cyclosporine, ketoconazole, ritonavir, clarithromycin, azithromycin, verapamil extended release [ER], and diltiazem ER) demonstrated threefold increases in colchicine concentrations with all agents except azithromycin [88]. The authors recommended colchicine dose reductions of $33-66 \%$ for the treatment of acute gout and $50-75 \%$ for prophylaxis when co-administered with CYP450 3A4 and P-gp inhibitors. No dose adjustments were recommended in the combination with azithromycin. Finally, a 50\% dose reduction of colchicine when combined with cyclosporin was recommended in another report [89].

In terms of adverse drug reactions (ADRs), colchicine seems to be well tolerated at therapeutic doses. In a recent systematic review of assessing the safety of colchicine, increases in the rate of diarrhea and gastrointestinal adverse events were observed. However, the rate of hepatic, sensory, muscular, infectious or hematological toxicities, or death was not increased [90].

Overall, the drug-drug interaction (DDI) profile of colchicine should be taken into consideration before its initiation in confirmed COVID-19 cases. That should be done in the context of both medications taken prior to hospital admission and medications administered in-house. In fact, the potential for DDIs in COVID-19 treatments and their possible competitive metabolic destiny should be studied by the application of pharmacogenomics in large scale.

In conclusion, colchicine could offer a viable treatment option in the fight against COVID-19-induced cytokine storm. Its relatively low cost and adequate availability make it a rather attractive option. However, caution should be exercised due to its potential for DDIs. In terms of efficacy, initial reports show limited promise. More specifically, in a trial of 105 patients randomly assigned to either standard treatment or standard treatment plus colchicine [91], the time to clinical deterioration was statistically significant in favor of the colchicine group. However, no differences were observed in high-sensitivity cardiac troponin or C-reactive protein levels. Furthermore, the study was underpowered which led the authors to advise caution in the interpretation of their results. Larger trials are required before safe conclusions can be reached.

\section{Hypothesis Generation for Clinical Trials}

\section{Safety Hypothesis}

The safety of colchicine in COVID-19 patients should be tested first. This will be done to make sure that no unexpected complications arise related to colchicine administration. The potential for opportunistic secondary super-infections, as well as for drug interactions has been previously described, therefore making such a trial of paramount importance. Considering the urgency of the current pandemic, this can be accomplished with an open-label trial of low-risk, symptomatic but not critically ill patients with close clinical and biochemical monitoring. The results of such a trial can then be compared to demographic controls. While a power analysis has not been performed, a reasonable number of 30-50 patients would be sufficient to provide statistically significant results.

\section{Efficacy Hypothesis 1}

The efficacy of colchicine should be assessed as a means of preventing complications related to COVID-19. As such, an open-label trial of hospitalized patients receiving colchicine and measuring the frequency of complications would provide sufficient evidence. The data generated from such a trial could then be compared to demographic controls. Again, a reasonable number of 30-50 patients would be sufficient to provide statistically significant results. 


\section{Efficacy Hypothesis 2}

The assessment of the efficacy of colchicine in the treatment of the acute complications related to COVID-19 would be the most challenging. Assuming hypotheses 1 and 2 have been tested with positive results, colchicine could then be added to standard therapy aimed against the cytokine storm. However, there are several challenges that will be difficult to overcome in this setting. Colchicine would have to be administered to critically ill patients, in conjunction with several other medications and invasive procedures. Therefore, measuring the absolute benefit of colchicine in that context would require larger sample sizes and more elaborate trial designs.

Authors' Contributions All authors contributed to the research conception and design. Research design, data collection, and interpretation were performed by Christodoulos Papadopoulos, Dimitrios Patoulias, and Eleftherios Teperikidis. Eleftherios Teperekidis and Dimitrios Mouselimis wrote the first draft version of the manuscript. Maria Toumpourleka, Aristi Boulmpou, Constantinos Bakogiannis, Michael Doumas, and Vassilios P. Vassilikos revised and edited it significantly in order to reach its final form. All authors read and approved the final version of manuscript.

Data Availability Not applicable.

\section{Compliance with Ethical Standards}

Conflict of Interest The authors declare that they have no conflict of interest.

Ethics Approval Not applicable.

Consent to Participate Not applicable.

Consent for Publication Not applicable.

Code Availability Not applicable.

\section{References}

1. Du Toit A. Outbreak of a novel coronavirus. Nat Rev Microbiol. 2020;18:123. https://doi.org/10.1038/s41579-020-0332-0.

2. Rothan HA, Byrareddy SN. The epidemiology and pathogenesis of coronavirus disease (COVID-19) outbreak. J Autoimmun. 2020;109:102433. https://doi.org/10.1016/j.jaut.2020.102433.

3. Organization WH. Coronavirus disease (COVID-2019) situation reports. In: World Health Organ. 2020. https://www.who.int/ emergencies/diseases/novel-coronavirus-2019/situation-reports. Accessed 17/05/2020

4. Jin Y, Yang H, Ji W, Wu W, Chen S, Zhang W, et al. Virology, epidemiology, pathogenesis, and control of COVID-19. Viruses. 2020;12:372. https://doi.org/10.3390/v12040372.

5. Ye Q, Wang B, Mao J. The pathogenesis and treatment of the 'cytokine storm' in COVID-19. J Inf Secur. 2020;80:607-13. https://doi.org/10.1016/j.jinf.2020.03.037.
6. Vaninov N. In the eye of the COVID-19 cytokine storm. Nat Rev Immunol. 2020;20:277. https://doi.org/10.1038/s41577-020-03056.

7. Dasgeb B, Kornreich D, McGuinn K, Okon L, Brownell I, Sackett DL. Colchicine: an ancient drug with novel applications. Br J Dermatol. 2018;178:350-6. https://doi.org/10.1111/bjd.15896.

8. Angelidis C, Kotsialou Z, Kossyvakis C, Vrettou AR, Zacharoulis A, Kolokathis F, et al. Colchicine pharmacokinetics and mechanism of action. Curr Pharm Des. 2018;24:659-63. https://doi.org/ 10.2174/1381612824666180123110042.

9. Leung YY, Yao Hui LL, Kraus VB. Colchicine - update on mechanisms of action and therapeutic uses. Semin Arthritis Rheum. 2015;45:341-50. https://doi.org/10.1016/j.semarthrit.2015.06.013.

10. Dalbeth N, Lauterio TJ, Wolfe HR. Mechanism of action of colchicine in the treatment of gout. Clin Ther. 2014;36:1465-79. https:// doi.org/10.1016/j.clinthera.2014.07.017.

11. Chen T, Wu D, Chen H, Yan W, Yang D, Chen G, et al. Clinical characteristics of 113 deceased patients with coronavirus disease 2019: retrospective study. BMJ. 2020;368:m1091. https://doi.org/ 10.1136/bmj.m1091.

12. Qin C, Zhou L, Hu Z, Zhang S, Yang S, Tao Y, et al. Dysregulation of immune response in patients with coronavirus 2019 (COVID-19) in Wuhan, China. Clin Infect Dis. 2020. https://doi.org/10.1093/ cid/ciaa248.

13. Wang F, Nie J, Wang H, Zhao Q, Xiong Y, Deng L, et al. Characteristics of peripheral lymphocyte subset alteration in COVID-19 pneumonia. J Infect Dis. 2020;221:1762-9. https:// doi.org/10.1093/infdis/jiaa150.

14. Peng YD, Meng K, Guan HQ, et al. Clinical characteristics and outcomes of 112 cardiovascular disease patients infected by 2019nCoV. Zhonghua Xin Xue Guan Bing Za Zhi. 2020;48:E004. https://doi.org/10.3760/cma.j.cn112148-20200220-00105.

15. Xie H, Zhao J, Lian N, Lin S, Xie Q, Zhuo H. Clinical characteristics of non-ICU hospitalized patients with coronavirus disease 2019 and liver injury: a retrospective study. Liver Int. 2020;40:1321-6. https://doi.org/10.1111/liv.14449.

16. Zhang Y, Zheng L, Liu L, et al. Liver impairment in COVID-19 patients: a retrospective analysis of 115 cases from a single centre in Wuhan city, China. Liver Int. 2020:14455. https://doi.org/10.1111/ liv.14455.

17. Wang L, Li X, Chen H, Yan S, Li D, Li Y, et al. Coronavirus disease 19 infection does not result in acute kidney injury: an analysis of 116 hospitalized patients from Wuhan, China. Am J Nephrol. 2020;51:343-8. https://doi.org/10.1159/000507471.

18. Ling L, So C, Shum HP, et al. Critically ill patients with COVID-19 in Hong Kong: a multicentre retrospective observational cohort study. Crit Care Resusc. 2020;22(2):119-125.

19. Guo T, Fan Y, Chen M, Wu X, Zhang L, He T, et al. Cardiovascular implications of fatal outcomes of patients with coronavirus disease 2019 (COVID-19). JAMA Cardiol. 2020;5:811. https://doi.org/10. 1001/jamacardio.2020.1017.

20. Madjid M, Safavi-Naeini P, Solomon SD, Vardeny O. Potential effects of coronaviruses on the cardiovascular system. JAMA Cardiol. 2020;5:831. https://doi.org/10.1001/jamacardio.2020. 1286.

21. Inciardi RM, Lupi L, Zaccone G, Italia L, Raffo M, Tomasoni D, et al. Cardiac involvement in a patient with coronavirus disease 2019 (COVID-19). JAMA Cardiol. 2020;5:819. https://doi.org/ 10.1001/jamacardio.2020.1096.

22. Guo W, Li M, Dong Y, et al. Diabetes is a risk factor for the progression and prognosis of COVID-19. Diabetes Metab Res Rev. 2020:e3319. https://doi.org/10.1002/dmrr.3319.

23. Maddaloni E, Buzzetti R. Covid-19 and diabetes mellitus: unveiling the interaction of two pandemics. Diabetes Metab Res Rev. 2020: e33213321. https://doi.org/10.1002/dmrr.3321. 
24. Wang X, Ding YQ. From SARS to COVID-19: pathogens, receptor, pathogenesis and principles of the treatment. Zhonghua Bing Li Xue Za Zhi. 2020;49:647-52. https://doi.org/10.3760/cma.j. cn112151-20200318-00220.

25. Yao XH, Li TY, He ZC, et al. A pathological report of three COVID-19 cases by minimally invasive autopsies. Zhonghua Bing Li Xue Za Zhi. 2020;49:E009. https://doi.org/10.3760/cma.j. cn112151-20200312-00193.

26. Conti P, Gallenga CE, Tete G, et al. How to reduce the likelihood of coronavirus-19 (CoV-19 or SARS-CoV-2) infection and lung inflammation mediated by IL-1. J Biol Regul Homeost Agents. 2020;34. https://doi.org/10.23812/editorial-conti-2

27. Conti P, Ronconi G, Caraffa A, et al. Induction of pro-inflammatory cytokines (IL-1 and IL-6) and lung inflammation by coronavirus-19 (COVI-19 or SARS-CoV-2): anti-inflammatory strategies. J Biol Regul Homeost Agents. 2020;34. https://doi.org/10.23812/conti-e

28. Das UN. Can bioactive lipids inactivate coronavirus (COVID-19)? Arch Med Res. 2020;51:282-6. https://doi.org/10.1016/j.arcmed. 2020.03.004.

29. Li K, Wu J, Wu F, Guo D, Chen L, Fang Z, et al. The clinical and chest CT features associated with severe and critical COVID-19 pneumonia. Investig Radiol. 2020;55:327-31. https://doi.org/10. 1097/RLI.0000000000000672.

30. Phadke M, Saunik S. COVID-19 treatment by repurposing drugs until the vaccine is in sight. Drug Dev Res. 2020. https://doi.org/10. $1002 /$ ddr.21666.

31. Solaimanzadeh I. Acetazolamide, nifedipine and phosphodiesterase inhibitors: rationale for their utilization as adjunctive countermeasures in the treatment of coronavirus disease 2019 (COVID-19). Cureus. 2020;12:e7343. https://doi.org/10.7759/cureus. 7343.

32. Stebbing J, Phelan A, Griffin I, Tucker C, Oechsle O, Smith D, et al. COVID-19: combining antiviral and anti-inflammatory treatments. Lancet Infect Dis. 2020;20:400-2. https://doi.org/10.1016/S14733099(20)30132-8.

33. Sun ML, Yang JM, Sun YP, Su GH. Inhibitors of RAS might be a good choice for the therapy of COVID-19 pneumonia. Zhonghua Jie He He Hu Xi Za Zhi. 2020;43:219-22. https://doi.org/10.3760/ cma.j.issn.1001-0939.2020.03.016.

34. Zhang R, Wang X, Ni L, di X, Ma B, Niu S, et al. COVID-19: melatonin as a potential adjuvant treatment. Life Sci. 2020;250: 117583. https://doi.org/10.1016/j.lfs.2020.117583.

35. Varrassi G. Warning against the use of anti-inflammatory medicines to cure COVID-19: building castles in the air. Adv Ther. 2020;37:1705-7. https://doi.org/10.1007/s12325-020-01321-1.

36. Hoffmann M, Kleine-Weber H, Schroeder S, et al. SARS-CoV-2 cell entry depends on ACE2 and TMPRSS2 and is blocked by a clinically proven protease inhibitor. Cell. 2020;181:271-280.e8. https://doi.org/10.1016/j.cell.2020.02.052.

37. Little P. Non-steroidal anti-inflammatory drugs and covid-19. BMJ. 2020;368:m1185. https://doi.org/10.1136/bmj.m1185.

38. Akodad M, Lattuca B, Nagot N, Georgescu V, Buisson M, Cristol JP, et al. COLIN trial: value of colchicine in the treatment of patients with acute myocardial infarction and inflammatory response. Arch Cardiovasc Dis. 2017;110:395-402. https://doi.org/10.1016/j. acvd.2016.10.004

39. Deftereos S, Giannopoulos G, Panagopoulou V, Bouras G, Raisakis K, Kossyvakis C, et al. Anti-inflammatory treatment with colchicine in stable chronic heart failure. JACC Heart Fail. 2014;2: 131-7. https://doi.org/10.1016/j.jchf.2013.11.006.

40. Kajikawa M, Higashi Y, Tomiyama H, Maruhashi T, Kurisu S, Kihara Y, et al. Effect of short-term colchicine treatment on endothelial function in patients with coronary artery disease. Int $\mathrm{J}$ Cardiol. 2019;281:35-9. https://doi.org/10.1016/j.ijcard.2019.01. 054.

41. Martínez GJ, Robertson S, Barraclough J, Xia Q, Mallat Z, Bursill $\mathrm{C}$, et al. Colchicine acutely suppresses local cardiac production of inflammatory cytokines in patients with an acute coronary syndrome. J Am Heart Assoc. 2015;4:e02128. https://doi.org/10. 1161/JAHA.115.002128.

42. Nidorf SM, Eikelboom JW, Budgeon CA, Thompson PL. Lowdose colchicine for secondary prevention of cardiovascular disease. J Am Coll Cardiol. 2013;61:404-10. https://doi.org/10.1016/j.jacc. 2012.10.027.

43. Raju NC, Yi Q, Nidorf M, Fagel ND, Hiralal R, Eikelboom JW. Effect of colchicine compared with placebo on high sensitivity Creactive protein in patients with acute coronary syndrome or acute stroke: a pilot randomized controlled trial. J Thromb Thrombolysis. 2012;33:88-94. https://doi.org/10.1007/s11239-011-0637-y.

44. Robertson S, Martínez GJ, Payet CA, Barraclough JY, Celermajer DS, Bursill C, et al. Colchicine therapy in acute coronary syndrome patients acts on caspase-1 to suppress NLRP3 inflammasome monocyte activation. Clin Sci. 2016;130:1237-46. https://doi.org/ 10.1042/CS20160090.

45. Sun A, Wang Y-P, Chia J-S, Liu BY, Chiang CP. Treatment with levamisole and colchicine can result in a significant reduction of IL6 , IL-8 or TNF- $\alpha$ level in patients with mucocutaneous type of Behcet's disease. J Oral Pathol Med. 2009;38:401-5. https://doi. org/10.1111/j.1600-0714.2009.00774.x.

46. Liebenberg J, Dold C, Olivier L. A prospective investigation into the effect of colchicine on tuberculous pericarditis. Cardiovase $\mathrm{J}$ Afr. 2016;27:350-5. https://doi.org/10.5830/CVJA-2016-035.

47. Sambola A, Roca Luque I, Mercé J, et al. Colchicine administered in the first episode of acute idiopathic pericarditis: a randomized multicenter open-label study. Rev Esp Cardiol (Engl Ed). 2019;72: 709-16. https://doi.org/10.1016/j.rec.2018.11.016.

48. Imazio M, Brucato A, Cemin R, Ferrua S, Maggiolini S, Beqaraj F, et al. A randomized trial of colchicine for acute pericarditis. N Engl J Med. 2013;369:1522-8. https://doi.org/10.1056/ NEJMoa1208536.

49. Imazio M, Belli R, Brucato A, Cemin R, Ferrua S, Beqaraj F, et al. Efficacy and safety of colchicine for treatment of multiple recurrences of pericarditis (CORP-2): a multicentre, double-blind, placebo-controlled, randomised trial. Lancet. 2014;383:2232-7. https:// doi.org/10.1016/S0140-6736(13)62709-9.

50. Imazio M, Bobbio M, Cecchi E, Demarie D, Demichelis B, Pomari F, et al. Colchicine in addition to conventional therapy for acute pericarditis. Circulation. 2005;112:2012-6. https://doi.org/10.1161/ CIRCULATIONAHA.105.542738.

51. Brucato A, Brambilla G, Adler Y, Spodick DH, Canesi B. Therapy for recurrent acute pericarditis: a rheumatological solution? Clin Exp Rheumatol. 2006;24:45-50.

52. Imazio M, Trinchero R, Brucato A, Rovere ME, Gandino A, Cemin $\mathrm{R}$, et al. COlchicine for the Prevention of the Post-pericardiotomy Syndrome (COPPS): a multicentre, randomized, double-blind, placebo-controlled trial. Eur Heart J. 2010;31:2749-54. https:// doi.org/10.1093/eurheartj/ehq319.

53. Imazio M. Colchicine for recurrent pericarditis (CORP). Ann Intern Med. 2011;155:409-14. https://doi.org/10.7326/0003-4819-155-7201110040-00359.

54. Imazio M, Bobbio M, Cecchi E, Demarie D, Pomari F, Moratti M, et al. Colchicine as first-choice therapy for recurrent pericarditis. Arch Intern Med. 2005;165:1987-91. https://doi.org/10.1001/ archinte.165.17.1987.

55. Gianni F, Solbiati M. Colchicine is safe and effective for secondary prevention of recurrent pericarditis. Intern Emerg Med. 2012;7: 181-2. https://doi.org/10.1007/s11739-012-0775-z.

56. Bessissow A, Agzarian J, Shargall Y, Srinathan S, Neary J, Tandon $\mathrm{V}$, et al. Colchicine for prevention of perioperative atrial fibrillation in patients undergoing lung resection surgery: a pilot randomized controlled study. Eur J Cardiothorac Surg. 2018;53:945-51. https:// doi.org/10.1093/ejcts/ezx422. 
57. Deftereos S, Giannopoulos G, Kossyvakis C, Efremidis M, Panagopoulou V, Kaoukis A, et al. Colchicine for prevention of early atrial fibrillation recurrence after pulmonary vein isolation. J Am Coll Cardiol. 2012;60:1790-6. https://doi.org/10.1016/j.jacc. 2012.07.031.

58. Deftereos S, Giannopoulos G, Efremidis M, Kossyvakis C, Katsivas A, Panagopoulou V, et al. Colchicine for prevention of atrial fibrillation recurrence after pulmonary vein isolation: midterm efficacy and effect on quality of life. Heart Rhythm. 2014;11:620-8. https://doi.org/10.1016/j.hrthm.2014.02.002.

59. Finkelstein Y, Shemesh J, Mahlab K, Abramov D, Bar-el Y, Sagie A, et al. Colchicine for the prevention of postpericardiotomy syndrome. Herz. 2002;27:791-4. https://doi.org/10.1007/s00059-0022376-5.

60. Imazio M, Brucato A, Ferrazzi P, Rovere ME, Gandino A, Cemin $\mathrm{R}$, et al. Colchicine reduces postoperative atrial fibrillation. Circulation. 2011;124:2290-5. https://doi.org/10.1161/ CIRCULATIONAHA.111.026153.

61. Imazio M, Brucato A, Ferrazzi P, Pullara A, Adler Y, Barosi A, et al. Colchicine for prevention of postpericardiotomy syndrome and postoperative atrial fibrillation. JAMA. 2014;312:1016-23. https://doi.org/10.1001/jama.2014.11026.

62. Tabbalat RA, Hamad NM, Alhaddad IA, Hammoudeh A, Akasheh BF, Khader Y. Effect of ColchiciNe on the InciDence of Atrial Fibrillation in open heart surgery patients: END-AF Trial. Am Heart J. 2016;178:102-7. https://doi.org/10.1016/j.ahj.2016.05. 006.

63. Zarpelon CS, Netto MC, Jorge JCM, Fabris CC, Desengrini D, Jardim MS, et al. Colchicine to reduce atrial fibrillation in the postoperative period of myocardial revascularization. Arq Bras Cardiol. 2016;107:4-9. https://doi.org/10.5935/abc.20160082.

64. Giannopoulos G, Angelidis C, Kouritas VK, Dedeilias P, Filippatos $\mathrm{G}$, Cleman MW, et al. Usefulness of colchicine to reduce perioperative myocardial damage in patients who underwent on-pump coronary artery bypass grafting. Am J Cardiol. 2015;115:1376-81. https://doi.org/10.1016/j.amjcard.2015.02.036.

65. Imazio M, Brucato A, Rovere ME, et al. Colchicine prevents early postoperative pericardial and pleural effusions. Am Heart J. 2011;162:527-532.e1. https://doi.org/10.1016/j.ahj.2011.05.017.

66. Meurin P, Lelay-Kubas S, Pierre B, Pereira H, Pavy B, Iliou MC, et al. Colchicine for postoperative pericardial effusion: a multicentre, double-blind, randomised controlled trial. Heart. 2015;101:1711-6. https://doi.org/10.1136/heartjnl-2015-307827.

67. Agzarian J, Bessissow A, Srinathan S, Devereaux PJ, Neary J, Decher W, et al. The effect of colchicine administration on postoperative pleural effusion following lung resection: a randomized blinded placebo-controlled feasibility pilot study $\dagger$. Eur J Cardiothorac Surg. 2018;53:822-7. https://doi.org/10.1093/ejcts/ ezx401.

68. Izadi Amoli A, Bozorgi A, HajHossein Talasaz A, Salehi Omran A, Mortazavi SH, Jalali A, et al. Efficacy of colchicine versus placebo for the treatment of pericardial effusion after open-heart surgery: a randomized, placebo-controlled trial. Am Heart J. 2015;170:1195201. https://doi.org/10.1016/j.ahj.2015.09.020.

69. Deftereos S, Giannopoulos G, Raisakis K, Kossyvakis C, Kaoukis A, Panagopoulou V, et al. Colchicine treatment for the prevention of bare-metal stent restenosis in diabetic patients. J Am Coll Cardiol. 2013;61:1679-85. https://doi.org/10.1016/j.jacc.2013.01. 055 .

70. Alabed S, Cabello JB, Irving GJ, et al. Colchicine for pericarditis. Cochrane Database Syst Rev CD010652. 2014. https://doi.org/10. 1016/j.acvd.2016.10.004.

71. Verma S, Eikelboom JW, Nidorf SM, al-Omran M, Gupta N, Teoh $\mathrm{H}$, et al. Colchicine in cardiac disease: a systematic review and meta-analysis of randomized controlled trials. BMC Cardiovasc Disord. 2015;15:96. https://doi.org/10.1186/s12872-015-0068-3.
72. Imazio M, Brucato A, Forno D, Ferro S, Belli R, Trinchero R, et al. Efficacy and safety of colchicine for pericarditis prevention. Systematic review and meta-analysis. Heart. 2012;98:1078-82. https://doi.org/10.1136/heartjnl-2011-301306.

73. Lotrionte M, Biondi-Zoccai G, Imazio M, Castagno D, Moretti C, Abbate A, et al. International collaborative systematic review of controlled clinical trials on pharmacologic treatments for acute pericarditis and its recurrences. Am Heart J. 2010;160:662-70. https:// doi.org/10.1016/j.ahj.2010.06.015.

74. Raval J, Nagaraja V, Eslick GD, Denniss AR. The role of colchicine in pericarditis - a systematic review and meta-analysis of randomised trials. Heart Lung Circ. 2015;24:660-6. https://doi. org/10.1016/j.hlc.2015.01.010.

75. Kumar M, Tandon V, Mosebach CM, et al. Acute myopericarditis with Crohn's disease flare-up. Cureus. 2019;11:e4248.

76. Sève $\mathrm{P}$, Stankovic K, Broussolle C. Effectiveness of colchicine in a case of recurrent compressive rheumatoid pericarditis. Rheumatol Int. 2005;25:558-61. https://doi.org/10.1007/s00296-004-0572-8.

77. Smilde BJ, Woudstra L, Fong Hing G, Wouters D, Zeerleder S, Murk JL, et al. Colchicine aggravates coxsackievirus B3 infection in mice. Int J Cardiol. 2016;216:58-65. https://doi.org/10.1016/j. ijcard.2016.04.144.

78. Maestroni S, Imazio M, Valenti A, Assolari A, Brucato A. Is colchicine really harmful in viral myocarditis? Int J Cardiol. 2017;229: 42. https://doi.org/10.1016/j.ijcard.2016.10.031.

79. Wiesenfeld PL, Garthoff LH, Sobotka TJ, Suagee JK, Barton CN. Acute oral toxicity of colchicine in rats: effects of gender, vehicle matrix and pre-exposure to lipopolysaccharide. J Appl Toxicol. 2007;27:421-33. https://doi.org/10.1002/jat.1198.

80. Finkelstein Y, Aks SE, Hutson JR, Juurlink DN, Nguyen P, Dubnov-Raz G, et al. Colchicine poisoning: the dark side of an ancient drug. Clin Toxicol. 2010;48:407-14. https://doi.org/10. 3109/15563650.2010.495348.

81. Fernandes F, Ramires FJA, Ianni BM, Salemi VMC, Oliveira AM, Pessoa FG, et al. Effect of colchicine on myocardial injury induced by Trypanosoma cruzi in experimental Chagas disease. J Card Fail. 2012;18:654-9. https://doi.org/10.1016/j.cardfail.2012.06.419.

82. Tardif J-C, Kouz S, Waters DD, Bertrand OF, Diaz R, Maggioni AP, et al. Efficacy and safety of low-dose colchicine after myocardial infarction. N Engl J Med. 2019;381:2497-505. https://doi.org/ 10.1056/NEJMoa1912388.

83. Dvorak Z, Modriansky M, Pichard-Garcia L, et al. Colchicine down-regulates cytochrome $\mathrm{P} 450$ 2B6, 2C8, 2C9, and 3A4 in human hepatocytes by affecting their glucocorticoid receptormediated regulation. Mol Pharmacol. 2003;64:160-9. https://doi. org/10.1124/mol.64.1.160.

84. Tateishi T, Soucek P, Caraco Y, Guengerich FP, Wood AJJ Colchicine biotransformation by human liver microsomes. Identification of CYP3A4 as the major isoform responsible for colchicine demethylation. Biochem Pharmacol. 1997;53:111-6. https://doi.org/10.1016/s0006-2952(96)00693-4.

85. Speeg KV, Maldonado AL, Liaci J, Muirhead D. Effect of cyclosporine on colchicine secretion by a liver canalicular transporter studied in vivo. Hepatology. 1992;15:899-903. https://doi.org/10. 1002/hep.1840150524.

86. Chen Y-J, Huang S-M, Liu C-Y, Yeh PH, Tsai TH. Hepatobiliary excretion and enterohepatic circulation of colchicine in rats. Int J Pharm. 2008;350:230-9. https://doi.org/10.1016/j.ijpharm.2007. 08.052.

87. Davis MW, Wason S. Effect of steady-state atorvastatin on the pharmacokinetics of a single dose of colchicine in healthy adults under fasted conditions. Clin Drug Investig. 2014;34:259-67. https://doi.org/10.1007/s40261-013-0168-8.

88. Terkeltaub RA, Furst DE, DiGiacinto JL, et al. Novel evidencebased colchicine dose-reduction algorithm to predict and prevent colchicine toxicity in the presence of cytochrome P450 3A4/P- 
glycoprotein inhibitors. Arthritis Rheum. 2011;63:2226-37. https:// doi.org/10.1002/art.30389.

89. Wason S, Digiacinto JL, Davis MW. Effect of cyclosporine on the pharmacokinetics of colchicine in healthy subjects. Postgrad Med. 2012;124:189-96. https://doi.org/10.3810/pgm.2012.07.2579.

90. Stewart S, Yang KCK, Atkins K, Dalbeth N, Robinson PC. Adverse events during oral colchicine use: a systematic review and meta-analysis of randomised controlled trials. Arthritis Res Ther. 2020;22:28. https://doi.org/10.1186/s13075-020-2120-7.
91. Deftereos SG, Giannopoulos G, Vrachatis DA, Siasos GD, Giotaki SG, Gargalianos P, et al. Effect of colchicine vs standard care on cardiac and inflammatory biomarkers and clinical outcomes in patients hospitalized with coronavirus disease 2019: the GRECCO-19 randomized clinical trial. JAMA Netw Open. 2020;3:e2013136. https://doi.org/10.1001/jamanetworkopen.2020.13136.

Publisher's Note Springer Nature remains neutral with regard to jurisdictional claims in published maps and institutional affiliations. 